Journal of the

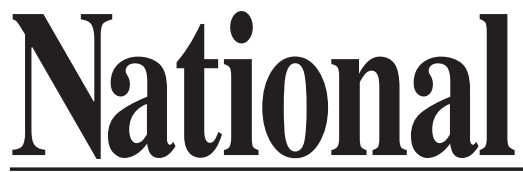

Academy or

Forensic
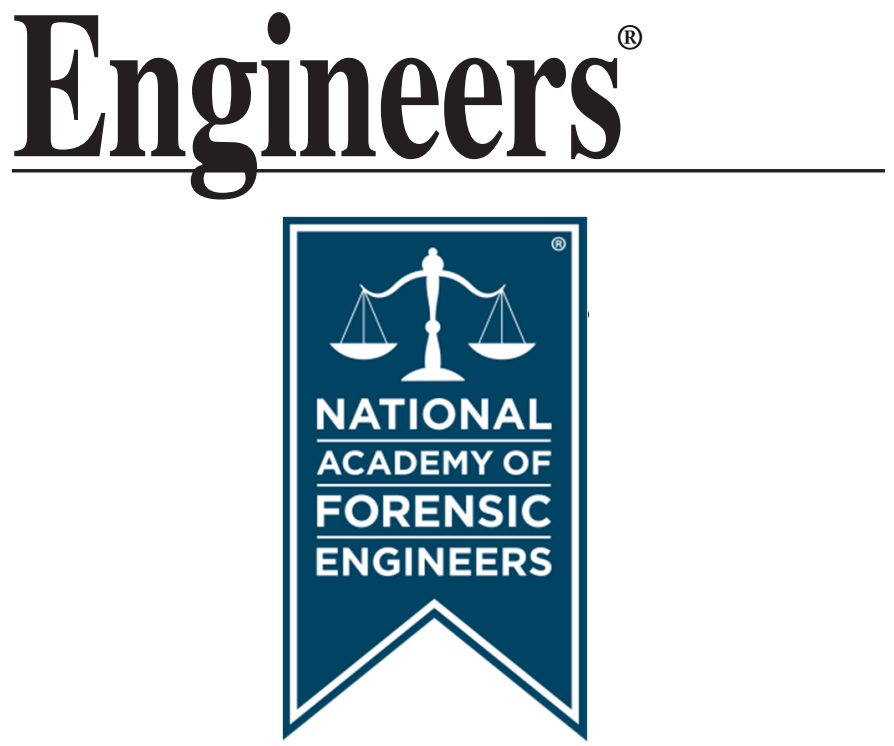

http://www.nafe.org ISSN: 2379-3252 


\section{Forensic Engineering Assessment of Safety for Stand Up Forklifts}

by Richard M. Ziernicki, Ph.D., P.E. (NAFE 308F)

Ben T. Railsback, P.E. (NAFE 713M)

\section{Introduction}

Forklifts operated from a stand up position rather than a seated position offer a significant advantage to increase warehouse capacity. Stand up lift trucks can be operated in warehouse aisles as narrow as 8 feet. In contrast, traditional sit down lift trucks typically require aisles approximately 11 feet wide. Aisle width reduction can increase warehouse capacity approximately 20 to 25 percent. However, a significant hazard exists with the use of stand up lift trucks that does not exist with sit down lift trucks; the hazard of a horizontal rack beam entering the operator compartment and crushing the operator. Sit down lift trucks are equipped with a roll over protective structure typically comprised of a canopy supported by four vertical posts. Stand up lift trucks are typically equipped with an overhead guard to protect the operator from falling objects, however, the rear of the canopy is not typically supported by posts. The overhead guard design leaves the rear of the operator compartment open, and horizontal rack beams can intrude into the operator compartment, crushing the operator between the rack and the lift truck. Hundreds of serious accidents have resulted from this hazard and over a dozen operators have sustained fatal injuries.

Another significant hazard related to stand up lift trucks is the hazard of a lower limb injury or foot crush due to the opening across the rear of the operator compartment. Numerous injuries have occurred to the lower limbs of stand up lift truck operators due to the close proximity of the operator's lower limbs to the exterior of the lift truck, and the confined areas that stand up lift trucks operate in. The operator's foot or leg can become pinned between the moving lift truck and a fixed object such as a rack system, column, or another lift truck. The accident database compiled by one of the stand up forklift manufacturers indicates that the manufacturer's stand up lift trucks have been involved in over 3,000 incidents/accidents in the last thirty years. Over 500 accidents involving lower limb injury/foot crush have occurred. Both foot crush injuries and horizontal intrusion injuries share a common theme; the operator becomes injured while the lift truck is traveling in a forks trailing manner (traveling with the forks or load end following the truck.) 
Copyright @ National Academy of Forensic Engineers (NAFE) http://www.nafe.org. Redistribution or resale is illegal. Originally published in the Journal of the NAFE volume indicated on the cover page. ISSN: 2379-3252

This paper will detail the hazards of horizontal intrusion and lower limb injury for the operators of stand up lift trucks, review standards related to operator protection against horizontal intrusion and lower limb injury, summarize a safety engineering analysis of the stand up lift truck design including guarding to mitigate the hazards, and present three cases tried to jury verdict regarding injury accidents on stand up lift trucks.

\section{Key Words}

Forensic Engineering, Stand Up Forklift, Safety, Guarding, Foot Crush, Horizontal Intrusion.

\section{Stand Up Lift Trucks}

Stand up lift trucks are produced in a variety of configurations. This paper is limited to narrow aisle stand up lift trucks that are end controlled, (controlled from the end opposite of the load), counterbalanced trucks, and reach/straddle trucks. An example of a stand up, end control, counterbalanced truck is shown in Figure 1, and an example of a stand up, end control, reach type truck is shown in Figure 2. Counterbalance trucks trans-

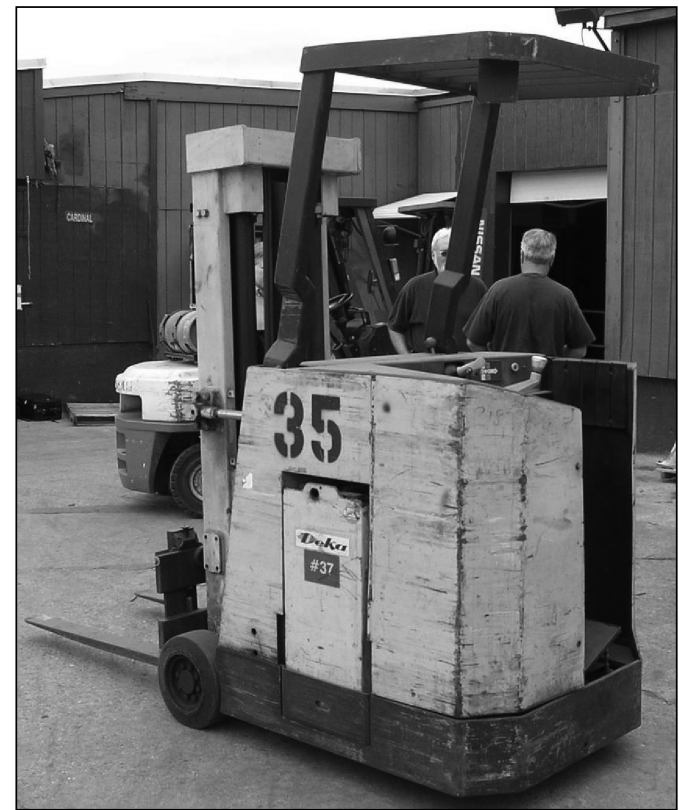

Figure 1

Crown RC30TT - Stand Up, End Control, Counterbalance Lift Truck

port their load outside of the polygon formed by points of contact between the tires of the truck and the ground while reach or straddle trucks transport the load (or a portion of the load) within the polygon formed by the points of contact between the tires and ground. The primary load tires on a counterbalance truck are located directly behind the mast of the truck, while the load wheels on a reach or straddle truck are located on outriggers in front of the truck.

The wheel configuration of the truck dictates the turning radius and subsequently the aisle width required by the truck. Counterbalanced trucks can pivot about a point between the left and right front load wheel and typically have a turning radius of approximately 4-5 feet, while reach and straddle trucks can turn about a point located midway between the front load wheels, and have a turning radius of approximately 5-6 ft. Because counterbalance trucks have a 
Copyright @ National Academy of Forensic Engineers (NAFE) http://www.nafe.org. Redistribution or resale is illegal. Originally published in the Journal of the NAFE volume indicated on the cover page. ISSN: 2379-3252

NAFE 308F/713M

SAFETY FOR STAND UP FORKLIFTS

PAGE 75

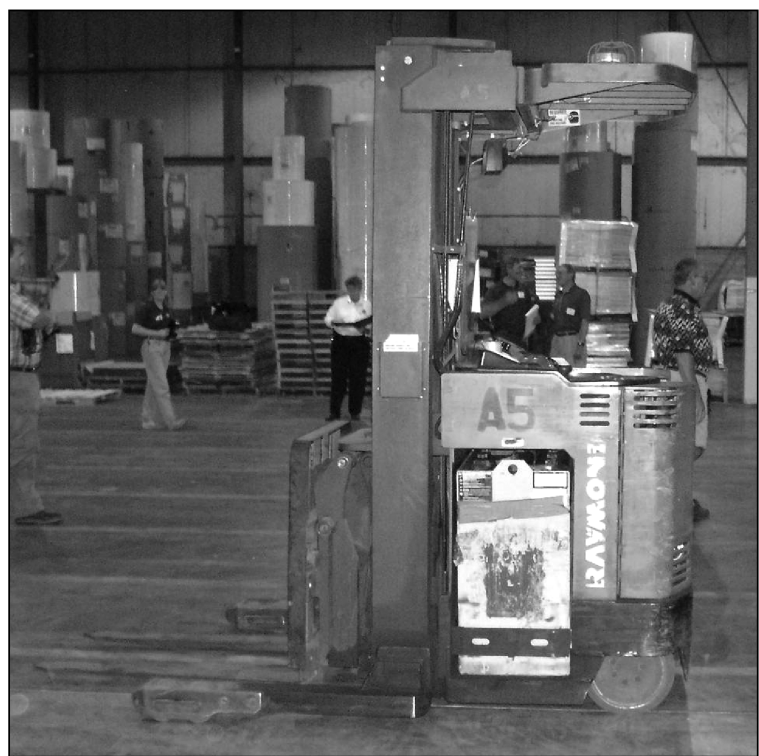

Figure 2

Raymond 31i-DR30TT - Stand Up, End Control, Deep Reach Truck

shorter wheelbase than reach trucks, counterbalance trucks can operate in slightly narrower aisles that reach trucks. Reach/Straddle or narrow aisle trucks can typically handle larger loads than counterbalance trucks, and lift loads to greater heights. Reach trucks are typically equipped with a pantograph or scissors mechanism to extend the load away from the mast. Straddle trucks utilize the same basic chassis as a reach truck, but are not equipped with a reach mechanism. The pantograph mechanism on a reach truck can be doubled to allow a load to be stacked twice as deep as a straddle truck can. The ability to stack product twice as deep creates additional storage space in warehouses in that it eliminates the need for as many aisles.

Reach and straddle trucks are primarily used in warehousing applications to place loads into and remove loads from warehouse racking systems. Reach/straddle trucks have been referred to as "portable elevators." Counterbalance trucks are typically used to transport loads within warehouses, but may also be used to unload highway truck trailers at the loading dock.

The weight associated with lift trucks is typically underappreciated. A typical stand up counterbalance truck may weigh 8,000 pounds (including the battery), and be capable of moving a 3,000 pound load. The mass of a fully loaded truck is comparable to 4 Honda Civic sedans. While the weight associated with trucks is underappreciated, the kinetic energy associated with a truck is much lower than that commonly experienced in automotive applications. The stand up counter balance truck may be capable of traveling at speeds on the order of 7-8 mph empty (speeds are typically lower when loaded). The kinetic energy of a fully loaded truck moving at top speed is equivalent to the kinetic energy of an automobile moving at twice the speed (approximately $14 \mathrm{mph}$ ). The kinetic energy of an automobile traveling $65 \mathrm{mph}$ has approximately 22 times the 
Copyright @ National Academy of Forensic Engineers (NAFE) http://www.nafe.org. Redistribution or resale is illegal. Originally published in the Journal of the NAFE volume indicated on the cover page. ISSN: 2379-3252

kinetic energy of a stand up counterbalanced lift truck. Therefore protecting the occupant of a lift truck should be simpler than protecting the occupant of an automobile from a kinetic energy management standpoint.

\section{Hazard of Horizontal Intrusion}

While the use of narrow aisle lift trucks decreases the area of the warehouse that must be devoted to aisles, the volume of material stored on pallets can also be increased to increase warehouse storage capacity. When the amount of material stored on a single pallet increases without increasing the width or depth of the pallet, the height of the load increases. To accommodate the increased height of the pallet and load, the height of the rack beams (or shelf heights) must be increased to accommodate the size of the load. When the height of the first rack beam from the floor is raised above the height of the rear wall of the operator compartment, and is lower than the overhead guard, the rack beam can intrude into the operator compartment.

The penetration of the rack beam into the operator compartment can occur with the truck moving at speeds as high as 7-8 miles per hour (mph). Such a collision would certainly cause significant injuries to the operators. However, the speed of the collision is not the most significant factor. Considering the mass of the truck, even a collision between the operator of a truck and a rack at 1-2 mph can produce substantial force, or can compress the operator between the truck

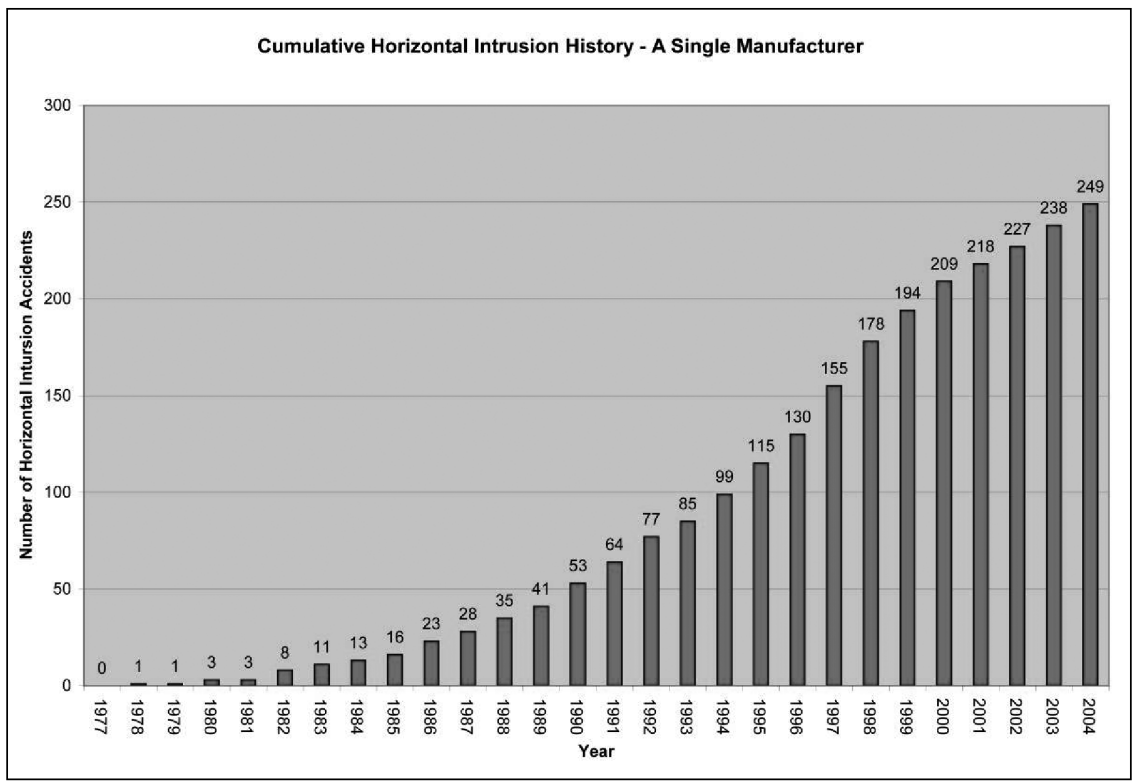

Figure 3

Cumulative Number of Horizontal Intrusion Incidents 
and rack, causing the operator to asphyxiate. Typically, operators that experience horizontal intrusion events sustain blunt trauma injuries or the operator may asphyxiate due to compression between the rack and the truck.

Statistics regarding the frequency and severity of horizontal intrusion incidents are not readily available. Some manufacturers of stand up lift trucks keep relatively detailed databases regarding incidents, while others do not retain records of incidents. OSHA records regarding incidents of horizontal intrusion are available however, the employee must have been injured and the employer must notify OSHA before a report can be generated. Review of one manufacturer's records indicates that over 250 incidents of horizontal intrusion have occurred on the manufacturer's stand up narrow aisle and counterbalanced lift trucks. The incidents include 12 fatalities and over 100 serious injuries over the past 30 years. Given the similarity between the stand up lift trucks manufactured by various manufacturers, it is likely that many more fatalities and significant injuries have occurred due to horizontal intrusion. Figure 3 details the cumulative horizontal intrusion incident record of one stand up lift truck manufacturer, and Figure 4 details the horizontal intrusion incident record of the manufacturer on an annual basis. The manufacturer detailed in Figure 3 and 4 began production of stand up lift trucks in the mid 1970's and did not begin tracking incidents until 1977.

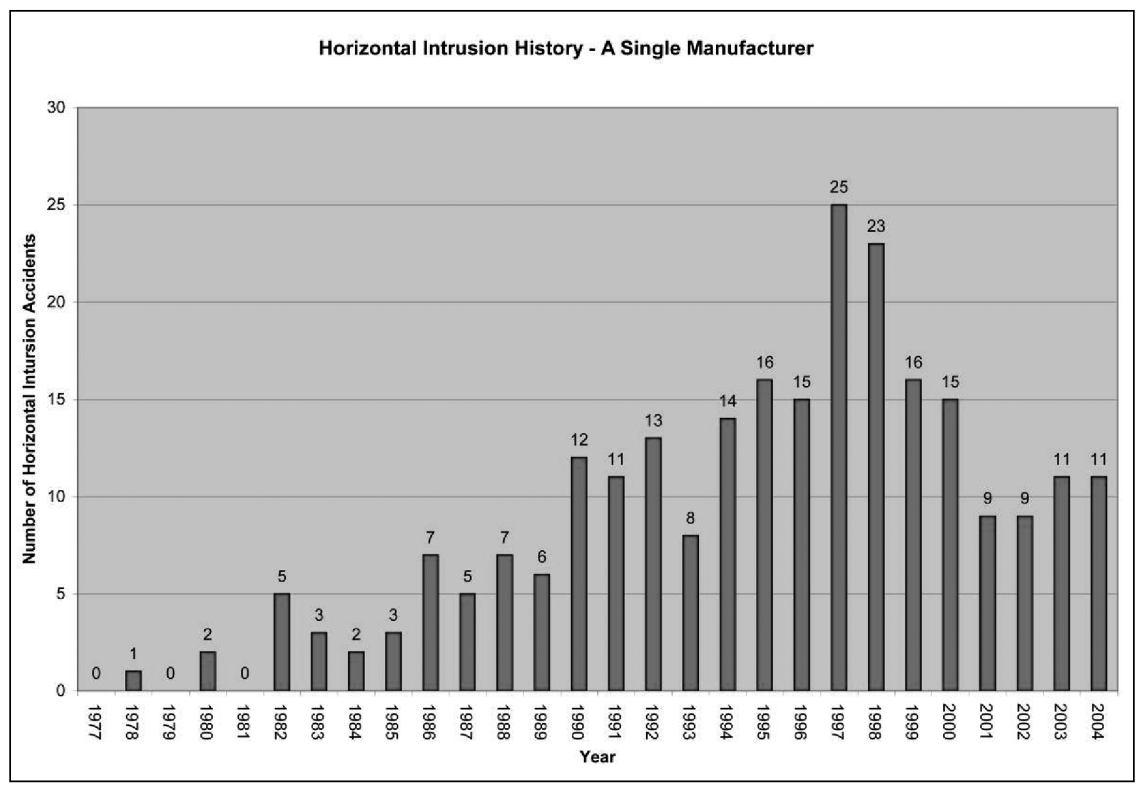

Figure 4

Annual Horizontal Intrusion Incident History 
Copyright @ National Academy of Forensic Engineers (NAFE) http://www.nafe.org. Redistribution or resale is illegal. Originally published in the Journal of the NAFE volume indicated on the cover page. ISSN: 2379-3252

\section{Hazard of Lower Limb Injury or Foot Crush}

The utility of the stand up lift truck is that it can be used in narrow aisles and increase warehouse capacity. The short wheelbase and small turning radius of the truck places the operator at the end of the truck. Typically the operator is surrounded on three sides by a skirt or wall around the truck, and the entrance to the rear of the truck is open. Because the operator is at the end of the truck, and the truck frequently comes into contact with racks, walls, and other fixed objects, a significant hazard exists when the lower limbs of the operator comes outside of the operator compartment. The lower limbs of the operator can be crushed between the truck and a fixed object, even when the collision between the truck and the fixed object occurs at low speed. The weight of the truck, approximately 8,000 pounds, means that even collisions at a low speed produce significant forces.

Stand up lift trucks are typically equipped with a "dead man" brake pedal. When the operator decelerates the truck by applying the service brakes, the operator is first required to raise a foot to apply the brakes. Therefore, the operator has already taken the weight off of one foot as the truck begins to decelerate. The deceleration of the truck through braking in combination with the operator standing on one foot has caused operators to lose their balance and potentially extend a foot outside of the operator compartment. In addition to deceleration and acceleration, the operator is subject to centrifugal acceleration during steering maneuvers. The location of the operator at the end of the truck away from the center of

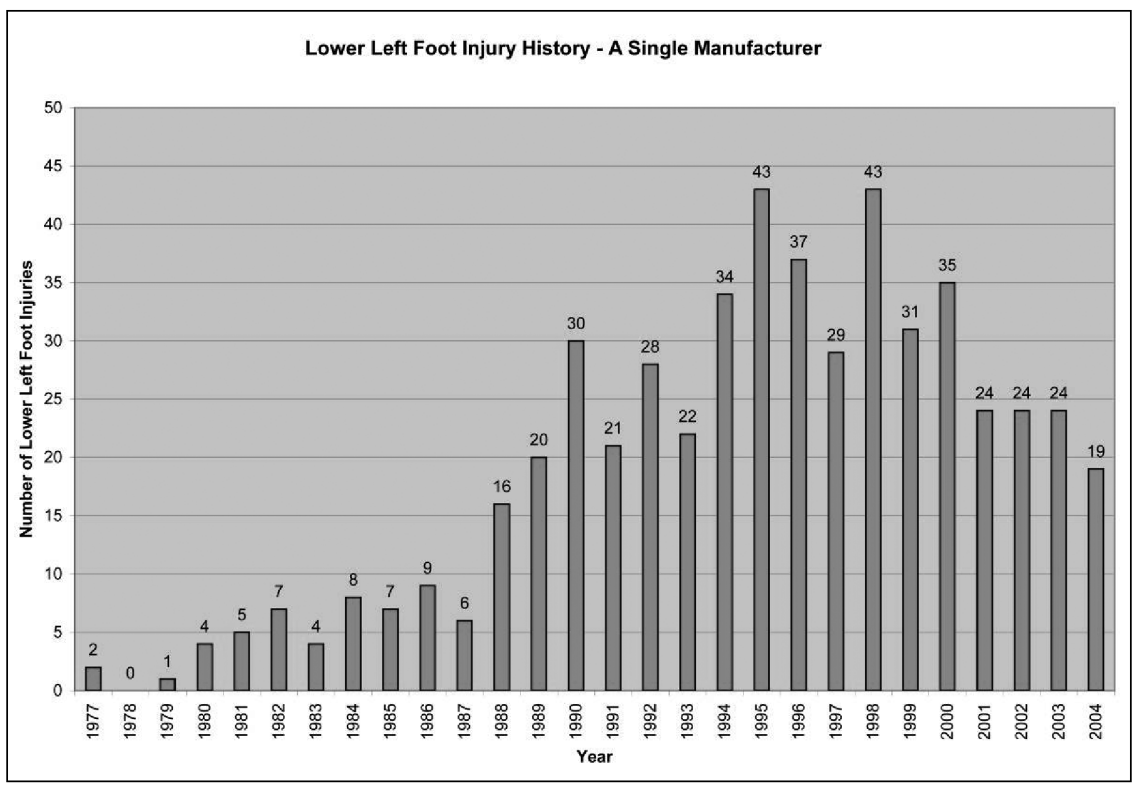

Figure 5

Annual Lower Limb Injury/Incident History 
Copyright $\odot$ National Academy of Forensic Engineers (NAFE) http://www.nafe.org. Redistribution or resale is illegal. Originally published in the Journal of the NAFE volume indicated on the cover page. ISSN: 2379-3252

NAFE 308F/713M

SAFETY FOR STAND UP FORKLIFTS

PAGE 79

rotation forces the operator towards the opening to the operator compartment. Both the acceleration/deceleration of the lift truck and the centrifugal acceleration can cause the operator to lose their balance and move a leg outside of the operator compartment. When the leg of the operator extends outside the operator compartment, the leg can be crushed between the truck and a fixed object, or the truck can run over the leg or foot of the operator when the foot is planted on the ground. Previous studies have examined the issue of longitudinal acceleration and deceleration and found the acceleration levels to cause loss of balance., ${ }^{1,2}$

Another injury mechanism that can occur to the lower limb of a stand up lift truck can occur due to intrusion into the operator compartment of the truck. When forklifts are traveling in queue, in a forks leading manner, and the following forklift fails to decelerate at the same time as the lead forklift, the forks on the trailing forklift can intrude into the operator compartment of the lead forklift.

Statistics regarding lower limb injury and foot crush have been compiled in several ways. As with horizontal intrusion some manufacturers keep detailed databases, while others do not. Because of the number of serious lower limb injuries a significant track record has become established in the legal system and attorneys involved in this litigation have established a significant database of lawsuits filed on this issue. OSHA records are also available to establish the frequency of injury. Figure 5 and Figure 6 detail the number of injuries and

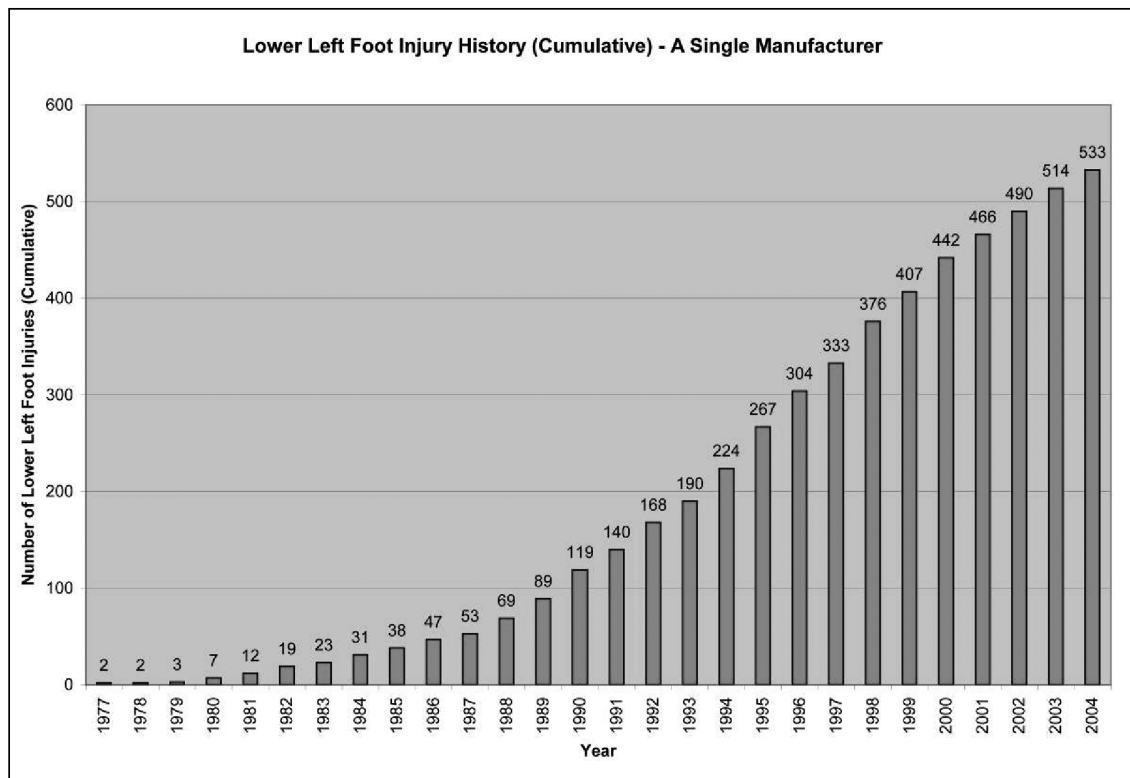

Figure 6

Cumulative Lower Limb Injury History 
Copyright ( $)$ National Academy of Forensic Engineers (NAFE) http://www.nafe.org. Redistribution or resale is illegal. Originally published in the Journal of the NAFE volume indicated on the cover page. ISSN: 2379-3252

incidence on a single manufacturer's stand up lift trucks. As with the charts detailing horizontal intrusion history, the manufacturer detailed in Figure 5 and 6 began production of stand up lift trucks in the mid 1970's and did not begin tracking incidents until 1977. The manufacturer's records indicate that over the last 30 years, over 500 accidents or incidents involving lower limb injury have occurred.

\section{Standards Regarding Operator Protection - Horizontal Intrusion}

Although awareness regarding the hazard of horizontal intrusion had existed for some time, the Industrial Truck Association (ITA) first addressed the issue of horizontal intrusion protection for operators with standards or recommended practices in 1989. The ITA is a trade association that represents the manufacturers of lift trucks in North America and has stated that it has established joint statistical and engineering programs to assist member manufacturers provide safe products. Membership in ITA is limited to manufacturers of lift trucks or suppliers of lift truck manufacturers, and ITA recommended practices are not available to the general public. In 1989 ITA issued a recommended practice for operator protection regarding horizontal intrusion for stand up, end controlled, narrow aisle and counterbalanced trucks. The recommended practice stated that:

"Means may be provided as part of the truck to limit intrusions into the operator's area of horizontal members (e.g. rack beams) oriented generally transverse to the direction of travel."

The recommended practice established testing conditions for the "means," or guard. The guard was to be tested at an impact speed of $1 \mathrm{mph}$ against a rigid barrier simulating a rack beam with a 3 inch vertical dimension. A guard successfully passing such a test would exhibit no more than 4 inches of deflection and would not exhibit separation of parts.

In 1990 the American Society of Mechanical Engineers (ASME) released addenda to the 1988 version of the B56.1 Safety Standard for Low Lift and High Lift Trucks. ${ }^{3}$ The standard addenda included a new section on operator protection for stand up, end controlled narrow aisle and counterbalanced trucks. The new section contains language similar to the ITA recommended practice. The standard states that:

"Guards or other means may be provided as part of the truck to limit intrusions into the operator's area of horizontal members (e.g. rack beams), oriented generally transverse to the direction of travel."

The testing conditions and criteria for successful guards are nearly identical to the criteria laid out in the ITA's recommended practice. Control of the B56.1 safety standard passed from ASME to the Industrial Truck Standards Development Foundation (ITSDF) in 2005. ITDSF is funded in part by the ITA. ${ }^{a}$ 
Copyright @ National Academy of Forensic Engineers (NAFE) http://www.nafe.org. Redistribution or resale is illegal.

Originally published in the Journal of the NAFE volume indicated on the cover page. ISSN: 2379-3252

NAFE 308F/713M

SAFETY FOR STAND UP FORKLIFTS

PAGE 81

\section{Standards Regarding Operator Protection - Lower Limb Injury or Foot Crush}

At least since the late 1960's the USAS/ASME/ITDSF B56.1 standard has mandated that the operator platform extend beyond the operator's position (apparently to prevent foot crushing injuries as the operator's foot overhangs the platform) ${ }^{4}$ Further the standards also indicate that the platform should be strong enough to withstand a significant compression load. In the 1960's the compression load was equal to the weight of the loaded truck, and currently the platform must withstand a compression load 2.5 times the weight of the loaded truck. Given that a loaded truck might weigh more than 10,000 pounds, the operator platform must be able to withstand a significant collision force. The requirement for an operator platform that must withstand significant compression load, in combination with discussion of operator enclosures, indicate that the lift truck industry was well aware of the foot crush hazard as early as the 1960's.

At least since the 1960's operator enclosures, or doors, have been permitted by the B56.1 standard, but the enclosure must allow the operator to egress or exit the truck quickly. By 1990, a paragraph had been added to the B56.1 standard indicating that "more or less guarding may be required to enhance safe operation." By 1993, the standard specifically referenced other sections of the standard related to horizontal intrusion protection and operator enclosures. In essence, the B56.1 standard transfers the responsibility for implementing guarding for horizontal intrusion and an operator enclosure to the owner or user of the truck.

The United Auto Workers and Ford have developed a "Basic Industrial Truck Standard" and an "Operator's Manual/Workbook." The standard mandates an "operator safety door" on rear entry riding stacker and reach trucks. The standard also mandates that the door be held in a normally closed position. ${ }^{5}$ The general trend in industry appears to indicate that sophisticated users of stand up lift trucks accept and endorse the use of doors on trucks. In contrast, most manufacturers are reluctant to provide doors as standard equipment.

\section{Safety Engineering Analysis}

Safety engineering is the science of applying scientific and engineering principles to the elimination and control of hazards. After a hazard has been recognized, a "design order of precedence" or "engineering hierarchy" of priorities may be used to effectively control a hazard. The hierarchy typically described in most safety engineering texts is as follows:

1. Eliminate the hazard by design. If the hazard cannot be eliminated by design, the following steps may be followed in succession to mitigate the risk of the hazard. 
Copyright @ National Academy of Forensic Engineers (NAFE) http://www.nafe.org. Redistribution or resale is illegal

Originally published in the Journal of the NAFE volume indicated on the cover page. ISSN: 2379-3252

2. Reduce the hazard through design.

3. Provide safety devices against the hazard.

4. Provide warnings about the hazard.

5. Provide training, instructions, and procedures.

6. Provide protective equipment.

Many references and standards now incorporate the engineering hierarchy to eliminate and control hazards associated with products and processes. ${ }^{6,7}$ However, the hazard must be recognized prior to the application of the hierarchy. The hazard of horizontal intrusion should have first been recognized during the design process. The forensic engineer can establish awareness of the hazard through several means (although lack of awareness does not necessarily relieve liability). Patents, injury incidents reports, OSHA records, or previous testimony can be used to establish awareness.

At a minimum, the hazard of horizontal intrusion into the operator compartment was well recognized by the late 1970's. In 1981 the Clark Equipment Company patented an overhead guard for lift trucks that had legs that connected the overhead guard to the chassis. The legs were specifically designed to resist forces on the guard imposed from behind or from the side of the truck. Later, the 1989 standards developed by the ITA and ASME for stand up lift trucks demonstrate industry recognition. The awareness of the hazard had existed from a substantially earlier period of time than the earliest standards as the result of accidents involving the use of stand up lift trucks. In a forensic safety engineering evaluation proving that the manufacturer is aware of the hazard can be established through the use of engineering standards, and previous incidents of the hazard resulting in injury. Even near misses or incidents involving the hazard that do not result in injury can create awareness of the risks associated with the hazard.

Many forklift manufacturers have in house policies regarding product liability, injury and loss prevention, or product design guides. Such documents typically contain statements that the manufacturer's products should be safe to use, and that the designer should consider both the use and misuse of the product. Similar to safety engineering principles, a policy developed by a significant manufacturer of stand up lift trucks states that when a hazard is recognized with a product a detailed list of steps is to be carried out by the manufacturer. The steps include notification of users of the product, development of a permanent solution to the hazard, supplying users with a modification kit, and verification of the installation of the kit.

A manufacturer of stand up lift trucks that has recognized the hazard of horizontal intrusion has recommended that all warehouses should be redesigned to 
Copyright @ National Academy of Forensic Engineers (NAFE) http://www.nafe.org. Redistribution or resale is illegal. Originally published in the Journal of the NAFE volume indicated on the cover page. ISSN: 2379-3252

reduce the hazard of intrusion. The warehouse redesign would include repositioning the first rack beam several inches from the floor, or positioning the first rack beam several feet above the floor but below the top of the rear of the tractor portion of the lift truck. The first option significantly increases the cost of the racking within a warehouse in that pallets of material that were previously resting on the ground must now be supported by racking. The second option of placing the first rack beam below the level of the tractor limits the height of the material (including pallet) that can be stored at ground level to approximately 48 inches. Documents produced in litigation indicate that few warehouses or users of stand up lift trucks have responded positively to this suggestion.

In contrast to the manufacturer who has suggested that all warehouses should be redesigned, other safety engineers have addressed the design of the stand up lift truck. An engineering design solution to eliminate the hazard and protect the operator from horizontal intrusion has not currently been identified. However, several styles of guards have been produced to protect the operator from horizontal intrusion. Vertical posts extending from the rear of the operator compartment to the overhead guard form an effective guard against rack beams entering the occupant compartment. Posts have been used for several decades by some manufacturers to protect the operator from horizontal intrusion by some manufacturers. Appendix A details the use of posts by various manufacturers. Arguments against the use of a post have been raised by some manufacturers in litigation. A rear post reduces visibility from the operator's position. A post located in close proximity to the operator may create a pinch or shear point when the operator is caught between the post and racking or a pallet. Currently several manufacturers are equipping trucks with a post(s) as a standard feature. Figure 6 is a Yale narrow aisle lift truck equipped with two posts.

A second guarding solution that has been implemented by several manufacturers is an extension of the skirt or wall surrounding the lift truck to a height of approximately 60 inches.

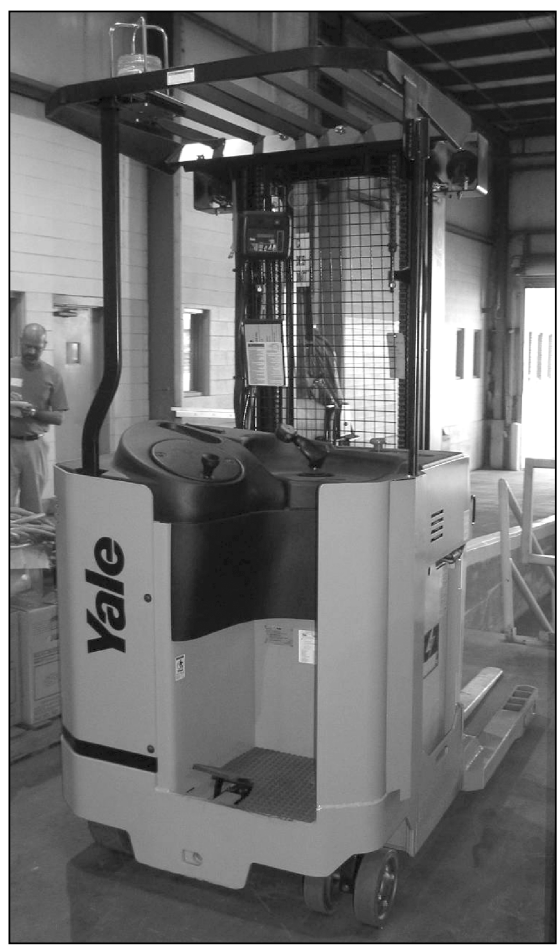

Figure 6

Yale Stand Up Narrow Aisle Reach Truck 
Copyright @ National Academy of Forensic Engineers (NAFE) http://www.nafe.org. Redistribution or resale is illegal Originally published in the Journal of the NAFE volume indicated on the cover page. ISSN: 2379-3252

Figure 7 is a photograph of a Caterpillar reach truck equipped with a "backrest extension" that extends the wall or skirt of the lift truck above the height of the first rack beam in a warehouse.

Both vertical post designs and backrest extension designs have been designed, tested, and implemented either as optional or standard equipment by lift truck manufacturers. Either option significantly reduces the probability or risk of a horizontal intrusion event injuring the operator of a stand up narrow aisle or counter balance truck.

Warnings and operation instructions have also been developed to warn and train the operator regarding the hazard of horizontal intrusion instead of providing a guard. However, safety engineering practice would indicate that warnings and training material should only supplement the available

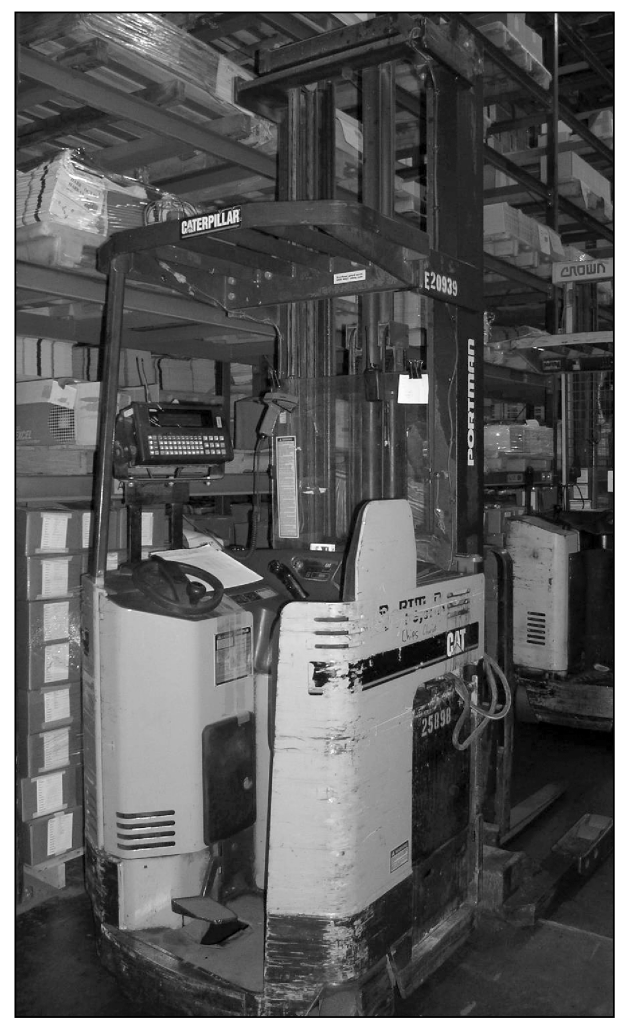

Figure 7

Caterpillar NRR45

Stand up Narrow Aisle Reach Truck design and guarding solutions to the hazard.

Another design solution to the hazard of horizontal intrusion is the use of a sit-down style truck. Traditional sit down trucks have four vertical posts supporting the roll over protective structure, and a horizontal rack beam cannot enter the operator compartment. Narrow aisle trucks with the operator seated transversely (perpendicular to the forks of the truck) have also been developed. Such trucks are often equipped with posts supporting the overhead guard that would prevent intrusion of a horizontal member into the occupant compartment. 
Copyright @ National Academy of Forensic Engineers (NAFE) http://www.nafe.org. Redistribution or resale is illegal.

Originally published in the Journal of the NAFE volume indicated on the cover page. ISSN: 2379-3252

NAFE 308F/713M

SAFETY FOR STAND UP FORKLIFTS

PAGE 85

\section{CASE STUDIES}

\section{Case Study \#1 - Operator v. Manufacturer - Horizontal Intrusion}

On March 30, 2000 at approximately 10:30 pm, the operator began a graveyard shift at a grocery warehouse in Kansas City, Missouri as an operator of a stand up counterbalance truck. On March 18, 2000, the warehouse had modified the steering on the operator's truck from a "reverse steering" machine to a "forward steering" machine in anticipation of a strike and a switch from union to nonunion employees. When traveling in forks first manner, a forward steering lift truck will turn to the right when the steering tiller is turned to the right. When a truck is equipped with reverse steering, traveling in a forks first manner, the truck will turn left when the steering tiller is turned to the right. The operator had approximately 9 years of experience working in a warehouse.

The warehouse requested that the operator work overtime, past the 7:00 am end of a typical graveyard shift. The operator continued to work on March 31 until approximately 12:06 pm when he was operating the lift truck in a forks trailing manner (operator compartment first) down an aisle. As the lift truck was traveling down the aisle, the operator noted that the lift truck was drifting towards the side of the aisle. The operator made a steering correction but input a steering correction toward the rack rather than away from the rack, apparently either due to fatigue or the recent change from reverse to forward steering.

The lift truck that the operator was using under rode the rack, and the rack beam came into forceful contact with the operator leaving witness marks on the back of his jacket. The operator sustained spinal column fractures and pelvic fractures as a result of the collision, and is a paraplegic as a result of the accident.

The operator sued the manufacturer of the lift truck and the case was tried in Kansas City, Missouri. The operator alleged that the lift truck was defective and should have been retrofit with a backrest extension guard, against horizontal intrusion protection.

Forensic engineering testimony was offered that the manufacturer was aware of the hazard, had designed guards against the hazard, and that the manufacturer had a responsibility to equip trucks with the guard. The case was tried to verdict and jurors found liability on the part of the grocery warehouse, and the manufacturer of the lift truck including punitive damages against the manufacturer. The manufacturer appealed the verdict and the case settled while on appeal. 
Copyright @ National Academy of Forensic Engineers (NAFE) http://www.nafe.org. Redistribution or resale is illegal. Originally published in the Journal of the NAFE volume indicated on the cover page. ISSN: 2379-3252

\section{Case Study \#2 - Operator v. Manufacturer - Horizontal Intrusion}

On August 1, 2003 at approximately 2:10 pm, an operator near the end of his shift was using a counter balance stand up lift truck to transport a load of chemicals into storage in a tanning facility. The operator dropped off the load, began to reverse the truck to turn around by traveling in a forks trailing direction. As the truck was traveling in a forks trailing direction, the truck under rode a small rack produced in-house at the tannery. The shelf of the rack intruded into the operator compartment pinning the operator between the shelf and the dashboard of the truck. The difference in height between the shelf and the console of the truck was approximately $51 / 2$ inches. The operator was working in an isolated area and reportedly died of asphyxiation.

Inspection of the truck after the accident did not reveal any significant control problems that would have caused the accident. The operator may have been preoccupied or distracted. As a result of the accident the estate of the operator filed suit against the manufacturer on the basis of a failure to fulfill a post sale duty to warn. Discovery revealed that the tannery had purchased the counterbalance lift truck used, and that at the time of the sale the manufacturer lost contact with the lift truck. Prior to the accident, the manufacturer came back into contact with the lift truck when the tannery inquired if the over head guard could be modified for a drive-in pallet racking system. At the time of the inquiry, the manufacturer could have provided notice of the hazard of horizontal intrusion, and had previously developed literature for that purpose. Further, the literature notified the user of the guarding options available to reduce the hazard.

The case was tried and reached a jury verdict in which the manufacturer was held liable for the post sale duty to warn. The case was tried in Portland, Maine which caps punitive damages awards. Based on the cap on punitive damages the lead attorney for the plaintiff elected not to pursue punitive damages.

\section{Case Study \#3 - Operator v. Manufacturer - Foot Crush}

A forklift operator in a warehouse near Lexington, Kentucky, reported that his accident occurred near the end of his day shift. He was reportedly operating the lift truck (Unit B) in a forks trailing manner (traveling with the forks of the unit following the operator) to the loading dock area in order to go outside to smoke a cigarette during his break. He reported that he was traveling at $1 / 4 \mathrm{max}$ imum speed as he passed a rack within the facility, Rack \#1, when he began slowing by decreasing the accelerator input. The operator then reportedly began braking by lifting his foot off of the service brake pedal about 5 or 6 feet from a second rack, Rack \#2. The operator reported that he was about 4 feet from Rack \#2 when he recognized that the lift truck was not going to stop as he intended, approximately 3 to $31 / 2$ feet from the rack. Since the lift truck was operating in a forks trailing manner without any protection against horizontal intrusion, the 
Copyright @ National Academy of Forensic Engineers (NAFE) http://www.nafe.org. Redistribution or resale is illegal. Originally published in the Journal of the NAFE volume indicated on the cover page. ISSN: $2379-3252$

NAFE 308F/713M

SAFETY FOR STAND UP FORKLIFTS

PAGE 87

operator stated that in order to avoid being "cut in half" by the horizontal beam of Rack \#2, he ducked down into the operator compartment. He furthermore stated that as he ducked down in the small operator compartment, he unintentionally moved his foot outside of the operator compartment, near the base of the left rear corner of the lift truck. As the operator ducked he apparently redirected the truck towards a vertical post supporting the rack. The operator stated that the lift truck was traveling "really slow" or was "just barely moving" at the point that the truck pinched his foot between the vertical rack post and the truck.

Another employee who worked for the same warehouse who had operated the Unit B lift truck prior to the accident stated that he had experienced brake problems with the truck. The employee reported that as a result of the brake problems the lift truck had collided with the "rollups" within the warehouse facility. As a result of the collision with the rollups, a brake fitting and the caster wheel bracket were damaged. A mechanic who serviced lift trucks onsite at the warehouse facility reportedly repaired the truck, including repairs to the braking system the day before the operator's accident.

A second employee of this warehouse, operated the Unit B lift truck prior to this operator's accident, and stated that the lift truck had problems with the braking system. She stated in an affidavit that the lift truck would not stop within a normal distance, or would stop too quickly.

The operator involved in the accident also reported that he had noticed fluid leaking from the Unit B lift truck several times prior to the accident. On the day of the accident, he reported seeing a fluid leak again, and reported the leak to the onsite mechanic. The onsite mechanic reportedly checked out the leak and determined that the brakes were in good condition.

Although the exact cause of the collision between the lift truck and the racking system has been disputed, the injuries to the operator could have been prevented had the lift truck been equipped with proper guarding. Vertical posts and/or a backrest extension would have provided the operator with guarding against the hazard of horizontal intrusion. A door across the rear of the operator compartment would have prevented the operator's left foot from coming outside of the lift truck as he ducked down in the compartment.

\section{Conclusions}

The hazards of lower limb injury (or foot crush) and horizontal intrusion into the operator compartment represent real hazards to the operators of stand up lift trucks with a significant risk of serious injury or death. Hazards to the operators of stand up lift trucks should be mitigated through the application of scientific and engineering principles and the use of an engineering hierarchy of 
Copyright @ National Academy of Forensic Engineers (NAFE) http://www.nafe.org. Redistribution or resale is illegal. Originally published in the Journal of the NAFE volume indicated on the cover page. ISSN: 2379-3252

design principles. The lift truck manufacturing industry has started to respond to the hazard of horizontal intrusion through the use of vertical posts and extended backrests to protect the operator. Some lift truck users and manufacturers have implemented the use of an operator compartment door and other preventative measures to reduce injuries to lower limbs. A new design of narrow aisle lift trucks with the operator in a seated position are also now available Further work is necessary to protect the operators of stand up lift trucks.

\section{Cited References}

1. Harris, Gerald F., and DeRosia, John. "Dynamic Postural Stability Testing During Standup Forklift (Lift Truck) Operation.” ASME International Mechanical Engineering Congress (2003).

2. Harris, Gerald F., and John Derosia. "Occupant Protection and Standup Forklift (Lift Truck) Dynamics." ASME International Mechanical Engineering Congress (2003).

3. ASME/ANSI B56.1b-1990 Addenda to ASME/ANSI B56.1-1988 Safety Standard for Low Lift and High Lift Trucks. American Society of Mechanical Engineers. New York: ASME, 1990.

4. USAS B56.1-1969 Safety Standard for Powered Industrial Trucks. American Society of Mechanical Engineers. New York: ASME, 1969.

5. ZA1-1992 Basic Industrial Truck Standards. Ford Manufacturing Standards. Ford Motor Company, 1992.

6. Safety of Machinery - Basic Concepts, General Principles for Design Part 1: Basic Terminology, Methodology. International Organization for Standardization. Geneva: ISO, 1992.

7. Spellman, Frank R., and Nancy E. Whiting. Safety Engineering Principles and Practices. 2nd ed. Lanham: Government Institutes, 2005. 6768.

a. www.indtrk.org/welcome.asp - "...ITA plays a role in funding ITDSF...” Jim Malvaso, The Raymond Corporation, President of ITA

\section{Other References:}

Berry, Thomas A. "Risk Based Study of Tipover and Off-Dock Accidents Involving Stand-Up Lift Trucks.” ASME International Mechanical Engineering Congress (2006). 